\title{
Low rates of hepatotoxicity among Asian patients with paracetamol overdose: a review of 1024 cases
}

\author{
Abd-Rahman Marzilawati ${ }^{1,2}$, Yen-Yew Ngau² and Sanjiv Mahadeva ${ }^{1 *}$
}

\begin{abstract}
Background: The metabolism of paracetamol in Asians is thought to differ from Westerners. Detailed clinical features of paracetamol -induced hepatotoxicity among Asians remains largely unreported.

Methods: A retrospective review of adult cases with paracetamol overdose over a five-year duration was performed in two of the largest public institutions in this country. Prevalence and predictive factors for hepatotoxicity were determined.

Results: Data on 1024 patients (median age 23 years, 82.0\% female, ethnic groups: Malays 40.8\%, Chinese 20.9\%, Indian 33.2\%) were obtained from January 2005 to December 2009. The median amount of paracetamol ingestion was 10.0 (IQR 5.0 - 15.0) $\mathrm{g}$ and the median serum paracetamol level was 274.80 (IQR $70.0-640.0) \mu \mathrm{mol} / \mathrm{L}$ at presentation. 75 (7.3\%) patients developed hepatotoxicity. 23/ 55 (41.8\%) patients who had ingested $>10 \mathrm{~g}$ of paracetamol and had a delayed (> 24 hour) administration of N-acetyl cystine (NAC) developed hepatotoxicity. No patients developed acute liver failure nor suffered any mortality (0\%). Independent predictors for hepatotoxicity were identified as Malay (OR 2.22, 95\% Cl=1.13-4.37) and Chinese (OR 3.26, 95\% Cl=1.55-6.84) ethnicity, paracetamol dose $>10 \mathrm{~g}(\mathrm{OR} 2.61,95 \% \mathrm{Cl}=1.53-4.46)$, prolonged duration of time from paracetamol ingestion to hospital presentation ( $>24$ hours $\mathrm{OR} 10.71,95 \% \mathrm{Cl}=3.46-33.15$ ) and prolonged duration of time from paracetamol ingestion to NAC administration (> 24 hours OR 9.02, 95\% Cl=2.97-27.45).
\end{abstract}

Conclusions: Paracetamol-induced hepatotoxicity rates in a multi-ethnic Asian population was low at 7.3\%. Mortality and morbidity were non-existent despite high doses of paracetamol ingestion and delayed presentations to hospital.

Keywords: Paracetamol, Acetaminophen, Hepatotoxicity, Acute liver failure, N-acetyl cysteine, Asian

\section{Background}

Paracetamol, or acetaminophen, overdose is a common means of self-poisoning worldwide due its wide availability and accessibility. It has been reported as the most common drug overdose either accidentally or unintentionally in the United Kingdom (UK), Europe, United States (US), and Australasia [1-3]. Paracetamol overdose is recognised to cause a range of hepatic damage from mild to severe hepatotoxicity, leading to acute liver failure (ALF) and death, despite the availability of antidote therapy. ALF resulting from paracetamol overdose has been extensively reported in the UK, US, France, Canada and Australia [4,5]. ALF due to paracetamol overdose

\footnotetext{
* Correspondence: sanjiv@ummc.edu.my

${ }^{1}$ Division of Gastroenterology, Department of Medicine, University of Malaya, Kuala Lumpur, Malaysia

Full list of author information is available at the end of the article
}

has been reported to be most common in the U.K. (60$75 \%$ of ALF aetiology), but less frequent in the U.S. (approximately $20 \%$ of ALF aetiology) and even lower in certain parts of Europe (2\% of ALF aetiology in France) $[4,6]$. However, in recent years, the incidence of paracetamol-induced ALF cases in the US has increased exponentially [7].

In a recent review article on the differences in aetiopathogenesis of ALF between Western and Eastern populations, it was reported that viral hepatitis remained the commonest cause of ALF in Asians. Paracetamol overdose resulting in ALF was believed to be infrequent in Asia due to differences in healthcare cultural practices and lack of availability of over-the-counter drugs [8]. Whilst the latter fact may be true in lesser developed countries, many rapidly developing Asian nations have a

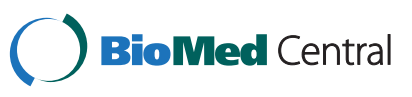


wide availability of over-the-counter drugs and cultural practices which are similar to the West. To date, two reports from small sample-sized studies in Hong Kong and Penang, Malaysia, have only demonstrated low rates of paracetamol-induced hepatotoxicity ranging from 2 $6 \%[9,10]$. Details on predictive factors for paracetamolinduced hepatotoxicity among Asians remain uncertain. This study aimed to examine the prevalence of hepatotoxicity in a large sample of adults with paracetamol overdose in a multi-ethnic Asian population, and determine predictive factors for hepatotoxicity in these patients.

\section{Methods}

\section{Study design and data collection}

Approval from the University Malaya Medical Centre (UMMC) ethics committee was obtained prior to the conduct of this study. In Malaysia, the majority of our urban population is concentrated in the capital, Kuala Lumpur. The UMMC, a 900-bedded hospital and the General Hospital of Kuala Lumpur (GHKL), a 1000bedded institution, are the two oldest and largest public institutions in the city. Both UMMC and GHKL have an estimated 110, 000 and 150,000 admissions to their Emergency Departments on an annual basis respectively (local institutional statistics 2008, unpublished). A retrospective review of clinical records was performed in both these centres for a five-year duration from 2005 to 2009. The International Classification and Diagnosis (ICD) 9 and 10 coding systems were used to identify individuals with paracetamol overdose from the Medical Records units of both institutions. All patients aged $\geq 18$ years of age who had a diagnosis of paracetamol overdose from ICD 9 and 10 coding system were included.

Information obtained from the medical records included the following: basic demography, timings of paracetamol overdose, presentation to Emergency Departments and administration of $\mathrm{N}$-Acetylcysteine (NAC), estimated doses of paracetamol ingested based on patient's recall, concomitant ingestion of other drugs, alcohol, history of psychiatric disorders and numbers of overdose attempts. All blood investigations during this period were available in both institutions' computerised laboratory database and the following data were collected: serum paracetamol level, liver function tests, $\mathrm{pH}$, coagulation profile and renal profile. The main outcomes in terms of duration of hospital stay and survival (i.e. discharged or died in hospital) were also available from both institutions' computerised data system.

\section{Definitions}

Hepatotoxicity was defined by a peak serum alanine transaminase (ALT) level $>1000 \mathrm{IU} / \mathrm{L}$, in accordance with previous accepted nomenclature in the literature
[11]. ALF was defined as the presence of coagulopathy (INR > 1.5) together with hepatic encephalopathy within 8-26 weeks of onset of symptoms in a patient without any prior liver disease [12].

\section{Statistics}

All results were analysed using the Statistical Package for Social Scientists (SPSS version 19.0, USA). Continuous variables were expressed as means with a standard deviation or medians where appropriate. Categorical data were expressed as proportions. Continuous data were analysed using Student's t-test, Mann-Whitney -U test and Kruskal Wallis test where appropriate. Categorical data were analysed with chi-square test or Fischer's exact test where appropriate. Significant associations with hepatotoxicity identified at univariate analysis were subsequently analysed in a multivariate analysis to identify independent predictors of hepatotoxicity. Predictive factors were expressed as odds ratios with a 95\% confidence interval. Statistical significance was defined as a $\mathrm{p}$ value of $<0.05$.

\section{Results}

Between January 2005 to December 2009, a total of 1,410 cases were identified as paracetamol overdose according to ICD 9 or ICD 10 coding systems in both UMMC and HKL. 386 cases were excluded due to a combination of missing medical records, coding misclassification and age $<18$ years. 1024 cases of medical records were finally available for analysis. The incidence of paracetamol overdoses from January 2005 to December 2009 in UMMC and KLGH are highlighted in Figure 1. In general, there had been an increase in incidence in both institutions from 2005 to 2006, with a steady rate of paracetamol overdose cases in the last 4 years. More cases of paracetamol overdose had been admitted to UMMC $(\mathrm{n}=583)$ compared to KLGH $(\mathrm{n}=441)$ during the period of study.

\section{Clinical characteristics of paracetamol overdose patients}

Demographic and clinical data of the study population are highlighted in Table 1 . The median age of adults with paracetamol overdose was 23 years, 840 (82.0\%) patients were female and the major ethnic group consisted of Malays $(n=418,40.8 \%)$. Paracetamol overdose resulted from deliberate self-harm in 885 (81.7\%) cases, unintentional overdose in 198 (18.3\%) cases and alcohol co-ingestion was not common $(n=46,4.2 \%)$. The clinical presentation of patients with paracetamol poisoning consisted mainly of gastrointestinal tract symptoms. 859 (79.3\%) of patients received NAC for their paracetamol overdose. 


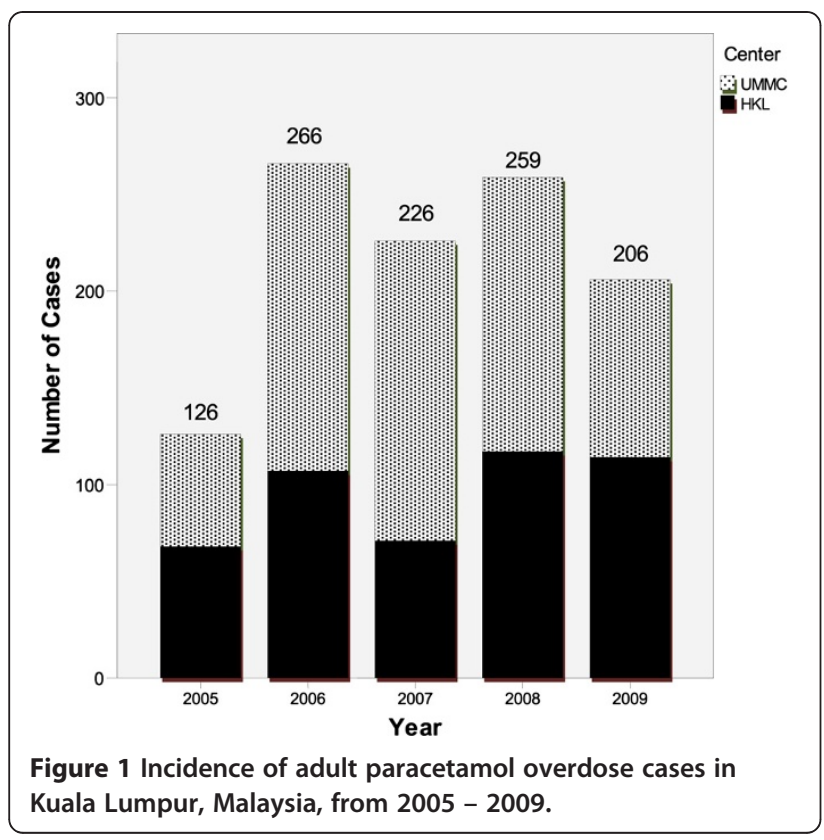

\section{Clinical details of paracetamol overdose}

The median amount of paracetamol ingestion in 1024 patients was 10.0 (IQR 5.0 - 15.0) $\mathrm{g}$ and the median serum paracetamol level was 274.80 (IQR 70.0 - 640.0) $\mu \mathrm{mol} / \mathrm{L}$ at presentation. The median duration from paracetamol ingestion to hospital presentation was 4.5 (IQR 2.3 - 11.5) hours. There was a median duration of 6.50 (IQR 2.5 - 14.0) hours from timing of paracetamol ingestion to NAC administration, whilst timing from hospital presentation to NAC administration was a median of 1.5 (IQR 0.0 to 4.1 ) hours, indicating that there was little delay in the administration of NAC at presentation to the emergency units in both hospitals. Most patients were admitted for a median of 3 days, ranging from $2-4$ days.

\section{Hepatotoxicity rates and clinical outcome}

$75(7.3 \%)$ patients with paracetamol overdose developed hepatotoxicity, i.e. a peak serum ALT $\geq 1000$ IU/L. 124 (12.1\%) patients had a moderately raised peak serum ALT (66-999 IU/L) whilst the remaining 825 (80.6\%) had normal liver function tests. 146 (14.3\%) cases had an INR $\geq 1.5$ but none of the patients with hepatotoxicity developed acute liver failure. 24/ 149 patients with mild drowsiness or stupor at presentation had an INR $>1.5$. However, 10 of these patients had alcohol intoxication and the remainder had co-ingestion or either benzodiazepines or antidepressants. All 1024 patients with paracetamol overdose were discharged well following hospitalisation. 542 patients had ingested $>10 \mathrm{~g}$ of paracetamol, but only 61 (11.3\%) developed hepatotoxicity. Among these 542 cases, 23/ 55 (41.8\%) patients who had a delayed ( $>24$ hours) administration of NAC developed hepatotoxicity.
Table 1 Demographic and clinical data on paracetamol overdose patients

\begin{tabular}{|c|c|c|}
\hline Category & n & (\%) \\
\hline Age (median, IQR) years & $23.00(20.00$ to 28.00$)$ & - \\
\hline \multicolumn{3}{|l|}{ Gender } \\
\hline Male & 184 & 18.0 \\
\hline Female & 840 & 82.0 \\
\hline \multicolumn{3}{|l|}{ Races } \\
\hline Malay & 418 & 40.8 \\
\hline Chinese & 214 & 20.9 \\
\hline Indian & 340 & 33.2 \\
\hline Others & 52 & 5.1 \\
\hline Previous History of Drug Overdose & 99 & 9.7 \\
\hline Previous History of paracetamol Overdose & 82 & 8.0 \\
\hline Previous Psychiatry History & 107 & 10.4 \\
\hline \multicolumn{3}{|l|}{ Drug Co-ingestion } \\
\hline Alcohol & 45 & 4.4 \\
\hline Benzodiazepine & 11 & 1.1 \\
\hline Antidepressant & 3 & 0.3 \\
\hline Anticonvulsant & 2 & 0.2 \\
\hline \multicolumn{3}{|l|}{ Clinical features } \\
\hline Nausea & 298 & 29.1 \\
\hline Vomiting & 576 & 56.2 \\
\hline Abdominal Pain & 333 & 32.5 \\
\hline Drowsiness & 149 & 14.6 \\
\hline Loss of Consciousness & 8 & 0.8 \\
\hline \multicolumn{3}{|l|}{ Circumstances } \\
\hline Deliberate & 836 & 81.6 \\
\hline Unintentional & 188 & 18.4 \\
\hline \multicolumn{3}{|l|}{ Treatment received } \\
\hline Charcoal & 425 & 41.5 \\
\hline Gastric Lavage & 486 & 47.5 \\
\hline N-Acetylcysteine & 859 & 79.3 \\
\hline
\end{tabular}

Predictive factors for paracetamol-induced hepatotoxicity Potential risk factors for paracetamol-induced hepatotoxicity were evaluated by univariate analysis (Table 2). Demographically, no specific age nor gender groups were found to have a risk of hepatotoxicity. However, a significant association with hepatotoxicity was observed with ethnicity (ethnic Indians $3.8 \%$ vs ethnic Malays $8.6 \%$ vs ethnic Chinese $12.1 \%$ ). Clinically, a paracetamol dose of $>10 \mathrm{~g}$ was associated with hepatotoxicity $(11.3 \%>10$ g vs $2.7 \%<10 \mathrm{~g}, \mathrm{p}<0.001)$, together with a prolonged duration of time from paracetamol ingestion to hospital presentation $(1.8 \%<3.9$ hours vs $8.6 \% 4-24$ hours vs $32.4 \%>24$ hours) and duration of time from paracetamol ingestion to NAC administration $(1.9 \%<3.9$ hours vs $8.7 \% 4-24$ hours vs $34.8 \%>24$ hours) (Table 2 ). 
Table 2 Risk factors for paracetamol-induced hepatotoxicity in study patients

\begin{tabular}{|c|c|c|c|c|c|c|c|c|}
\hline \multirow[t]{2}{*}{ Category } & \multicolumn{2}{|c|}{ Hepatotoxicity } & \multirow[t]{2}{*}{ Unadjusted OR } & \multirow[t]{2}{*}{$95 \% \mathrm{Cl}$} & \multirow[t]{2}{*}{$p$ value } & \multirow[t]{2}{*}{ Adjusted OR } & \multirow[t]{2}{*}{$95 \% \mathrm{Cl}$} & \multirow[t]{2}{*}{$p$ value } \\
\hline & Yes $n=75$ & No $n=949$ & & & & & & \\
\hline \multicolumn{9}{|l|}{ Age(years) } \\
\hline$<20$ & $18(5.9)$ & $288(94.5)$ & 1.00 & & 0.33 & 1.00 & & 0.31 \\
\hline $21-30$ & $47(8.4)$ & 510(91.6) & 1.48 & $0.84-2.59$ & 0.18 & 1.41 & $0.75-2.63$ & 0.29 \\
\hline$>30$ & $10(6.2)$ & 151(93.8) & 1.06 & $0.48-2.35$ & 0.89 & 0.82 & $0.34-2.00$ & 0.67 \\
\hline \multicolumn{9}{|l|}{ Gender } \\
\hline Female & $60(7.1)$ & $780(92.9)$ & 1.00 & & & & & \\
\hline Male & $15(8.2)$ & $169(91.8)$ & 1.15 & $0.64-2.08$ & 0.64 & NA & NA & NA \\
\hline \multicolumn{9}{|l|}{ Race } \\
\hline Indian & $13(3.8)$ & $327(96.2)$ & 1.00 & & 0.002 & 1.00 & & 0.007 \\
\hline Malay & $36(8.6)$ & $382(91.4)$ & 2.31 & $1.23-4.34$ & 0.009 & 2.22 & $1.13-4.37$ & 0.023 \\
\hline Chinese & $26(12.1)$ & $188(87.9)$ & 3.39 & $1.73-6.64$ & $<0.001$ & 3.26 & $1.55-6.84$ & 0.002 \\
\hline \multicolumn{9}{|c|}{ PCM\# Dose (g) } \\
\hline$<10$ & $12(2.7)$ & 436(97.3) & 1.00 & & & 1.0 & & \\
\hline$>10$ & $61(11.3)$ & $481(88.7)$ & 2.59 & $1.68-3.99$ & $<0.001$ & 2.61 & $1.53-4.46$ & $<0.001$ \\
\hline \multicolumn{9}{|c|}{ Alcohol Co-ingestion } \\
\hline Yes & $3(6.7)$ & 42(93.3) & 1.00 & & & & & \\
\hline No & $72(7.4)$ & $907(92.6)$ & 1.11 & $0.34-3.67$ & 0.87 & NA & NA & NA \\
\hline \multicolumn{9}{|c|}{ BZDP* Co-ingestion } \\
\hline No & $73(7.2)$ & $940(92.8)$ & 1.00 & & & & & \\
\hline Yes & $2(18.2)$ & $9(81.8)$ & 2.95 & $0.63-13.91$ & 0.17 & 3.20 & $0.60-17.68$ & 0.18 \\
\hline \multicolumn{9}{|c|}{ Time from PCM Ingestion to Hospital Presentation (hours) } \\
\hline$<3.9$ & $9(1.9)$ & 454(98.1) & 1.00 & & $<0.001$ & 1.00 & & $<0.001$ \\
\hline 4.0-24.0 & $43(8.7)$ & 452(91.3) & 5.00 & $2.42-10.34$ & $<0.001$ & 3.45 & $1.60-7.43$ & 0.001 \\
\hline$>24.1$ & 23(34.8) & $43(65.2)$ & 25.50 & $11.17-58.24$ & $<0.001$ & 10.71 & $3.46-33.15$ & $<0.001$ \\
\hline \multicolumn{9}{|c|}{ Time from PCM Ingestion to NAC administration (hours) } \\
\hline$<3.9$ & $5(1.5)$ & $332(98.5)$ & 1.00 & & $<0.001$ & 1.00 & & $<0.001$ \\
\hline 4.0-24.0 & $41(6.8)$ & $560(93.2)$ & 4.95 & $1.94-12.62$ & 0.001 & 2.94 & $1.07-8.00$ & 0.037 \\
\hline$>24.1$ & $29(34.1)$ & $56(65.9)$ & 36.31 & $13.54-97.40$ & $<0.001$ & 9.02 & $2.97-27.43$ & $<0.001$ \\
\hline
\end{tabular}

\# PCM - paracetamol.

* BZDP - benzodiazepines.

Independent predictors of paracetamol-induced hepatotoxicity, explored by logistic regression analysis, were found to include the following: Malay (OR 2.22, 95\% CI = 1.13-4.37) and Chinese (OR 3.26, 95\% CI = 1.55-6.84) ethnicity, paracetamol dose $>10 \mathrm{~g}$ (OR 2.61, 95\% CI $=1.53$ 4.46), prolonged duration of time from paracetamol ingestion to hospital presentation (4-24 hours OR 3.45, 95\% $\mathrm{CI}=1.60-7.43$; > 24 hours OR $10.71,95 \% \mathrm{CI}=3.46-33.15$ ) and prolonged duration of time from paracetamol ingestion to NAC administration (4-24 hours OR 2.94, 95\% $\mathrm{CI}=1.07-8.00$; > 24 hours OR 9.02, 95\% CI = 2.97-27.45).

\section{Discussion}

This retrospective study represents one of the largest case series of paracetamol overdoses that has been reported to date. The duration of 5 years demonstrated little variation in admission patterns (apart from the first year) and there had been no major changes in the medical management of paracetamol overdose during this period. As all cases of poisoning in this country are solely managed in public institutions, the data from this study is fairly representative of the population from the largest city in this country. Furthermore, the general Malaysian urban population consists of 3 major ethnic groups, i.e. Malays, Chinese and Indians [13]. Hence, our study has relevance to other populations in Asia as well.

In this study, we have demonstrated that despite significant numbers of paracetamol overdose over a 5-year duration, only $7.3 \%$ of this multi-ethnic Asian adult 
population developed hepatotoxicity and no (i.e. $\mathrm{n}=0$ ) patients developed ALF following paracetamol overdose. Our results are in concurrence with previous reviews that paracetamol overdose is a rare cause of ALF in Asians. It is noteworthy that $>50 \%$ of patients who ingested $>10 \mathrm{~g}$ of paracetamol and had a delayed ( $>24$ hours after paracetamol ingestion) administration of NAC did not develop hepatotoxicity. Whilst the usual characteristics of paracetamol pharmacology such as cumulative dose and delayed timing of NAC administration predicted hepatotoxicity, this study identified that ethnicity, particularly those of Malay (OR 2.22) and Chinese (OR 3.26), were independent determinants of hepatotoxicity. The latter fact may suggest, but does not confirm, that ethnic differences in paracetamol metabolism may contribute towards paracetamol-induced hepatotoxicity.

We have compared our case series with previous publications and summarised the salient features in Table 3. Paracetamol-induced hepatotoxicity rates, using a similar definition as ours, in Western patients have been reported to range from $15 \%$ to $36 \%[5,9,10,14-22]$. The only exception was a study from Edinburgh, UK, which reported a $4 \%$ rate of hepatotoxicity among 987 patients with paracetamol overdose, but patients who presented $>15$ hours post paracetamol ingestion had been excluded [21]. Paracetamol overdose had a mortality rate of up to $7 \%$ despite NAC administration, although mortality rates have declined over time due to successful liver transplantation in many centres. In contrast to Caucasian patients in Western studies, two publications from Asia and a single study from the Caribbean have reported hepatotoxicity rates ranging from $2 \%$ to $7 \%[9,10,19]$. Acute liver failure was not a feature and no mortality had been reported in the latter case series. The data from our large case series of 1024 patients appears to mirror the findings from these earlier smaller sample-sized studies.
A possible explanation for the lower hepatotoxicity rates in non-Western studies may be explained by the cumulative dose of paracetamol ingested by individuals. The minimal amount of paracetamol known to cause toxicity in adults is approximately $7.5 \mathrm{~g}$ and liver toxicity is usually associated with paracetamol doses of $>10 \mathrm{~g}$ [23]. In our study, we estimated that $52 \%$ of patients had ingested $>10 \mathrm{~g}$ of paracetamol and the median dose in our population was $10 \mathrm{~g}$. In several of the studies that have been reported from Western centres, the mean or median doses of paracetamol ingested have been reported to be higher, although not in all $[17,21,22]$. The mean/ median doses of paracetamol ingested in studies from the U.K., U.S. and Denmark have been reported as $15 \mathrm{~g}, 18 \mathrm{~g}$ and $25 \mathrm{~g}$ respectively (Table 3). However, other studies on Caucasian populations with similar median paracetamol doses (to ours) still reported higher hepatotoxicity rates of $14-31 \%$ (Table 3 ). An additional point is that NAC administration in our patients was based on normalised dosing. Asian patients may have inadvertently received higher NAC doses compared to Western patients of a higher averaged body weight.

An alternative explanation for an increased paracetamolinduced hepatotoxicity among Western patients may be related to alcohol co-ingestion. Chronic alcohol exposure is recognised to increase short term toxicity from paracetamol overdose by 2 to 3 fold increase in hepatic content of cytochrome P4502E1, the major isoform responsible for the generation of the toxic metabolite from paracetamol [24]. About 25\% of Western patients with paracetamol overdose were documented to have a regular alcohol consumption and excessive alcohol co-ingestion with paracetamol overdose was reported in $20-40 \%$ of cases $[14,15,18]$. In contrast, the rate of alcohol co-ingestion was only $4.2 \%$ in our study and $10-17 \%$ in other Asian studies [10,19].

Variation in the timing of NAC administration may be another explanation for differences in hepatotoxicity

Table 3 Summary of studies that have examined hepatotoxicity rates in patients with paracetamol overdose

\begin{tabular}{|c|c|c|c|c|c|c|}
\hline Author & Year & Location & n & Hepatotoxicity \% & Survival \% & Paracetamol Dose \\
\hline Proudfoot [22] & 1970 & Edinburgh, U.K. & 41 & $39 \%$ & $97.6 \%$ & $39 \%>15 \mathrm{~g}$ \\
\hline Schiodt [14] & 1997 & Texas, U.S. & 71 & $32 \%$ & $93 \%$ & 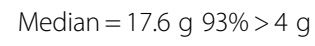 \\
\hline Hawton [17] & 1996 & Oxford, U.K. & 80 & $31 \%$ & NA & $69 \%>12.5 \mathrm{~g}$ \\
\hline Gyamlani [15] & 2001 & New York, USA & 93 & $16 \%$ & $98 \%$ & NA \\
\hline James [16] & 2008 & USA & 157 & $15 \%(1.3 \%$ ALF $)$ & $100 \%$ & Mean $18 \mathrm{~g}$ \\
\hline Ayonrinde [5] & 2005 & Australia & 188 & $14 \%$ & $100 \%$ & Median $=12 \mathrm{~g}$ \\
\hline Mohd-Zain [9] & 2006 & Penang, Malaysia & 165 & $7.3 \%$ & $100 \%$ & $38 \%>10 \mathrm{~g}$ \\
\hline Current study & 2011 & Kuala Lumpur, Malaysia & 1024 & $7.5 \%$ & $100 \%$ & Median $10 \mathrm{~g}(54.3 \%>10 \mathrm{~g})$ \\
\hline Chan [10] & 1993 & Hong Kong & 104 & $6 \%$ & $100 \%$ & Median $5 \mathrm{~g} 6.7 \%>10 \mathrm{~g}$ \\
\hline Mills [19] & 2008 & Jamaica & 49 & $2 \%$ & $100 \%$ & Range $2-30 \mathrm{~g}$ \\
\hline Schmidt [18] & 2002 & Copenhagen, Denmark & 737 & No data on hepatotoxicity (0.9\% ALF) & $99.9 \%$ & Median $25 \mathrm{~g}$ \\
\hline
\end{tabular}


rates between studies. Delayed administration of NAC to patients with potentially toxic doses of paracetamol is a recognised risk factor for hepatotoxicity, an observation that was also demonstrated in our study. Patients with paracetamol overdose who had received NAC $>24$ hours after paracetamol ingestion in our study were 10.4 times more likely to develop hepatotoxicity compared to those who received NAC earlier. Among our study cases, 92\% of patients received NAC within 24 hours. Unfortunately, data on the timing of NAC administration has not been reported widely in the literature, and further comparisons have not been possible. However, it is notable that despite $80 \%$ of patients receiving NAC within 24 hours of paracetamol overdose a $14 \%$ hepatotoxicity rate (i.e. double the rate in our study) was reported in a recent Australian study [5].

Pharmacogenetic variation in the metabolism of paracetamol between Caucasians and Orientals has previously been studied [25]. In a study comparing urinary excretion of paracetamol metabolites in 125 Caucasians and 33 ethnic Chinese, heterogeneity in the conversion of paracetamol cysteine conjugates (toxic paracetamol metabolites) to mercapturate via $\mathrm{N}$-acetylation had been demonstrated. Adults with Chinese ethnicity demonstrated relatively extensive glucuronidation but lower sulfation in paracetamol metabolism, when compared to Caucasians. Whilst clinical relevance of this variation in metabolic pathways remains uncertain, it is possible that intrinsic differences in the pharmacogenetics of paracetamol metabolism may be a major reason for differences in hepatotoxicity between Asians and Caucasians.

\section{Conclusions}

This study has obvious limitations in the light of its' retrospective design. Nevertheless, its' large sample size, representative study population and accurate capture of computerised laboratory data are its' major strengths. We have demonstrated that the rates of hepatotoxicity among 1024 Asian patients with paracetamol overdose is low at 7.3\%. Although differences in the clinical characteritics of paracetamol overdose between Western and Asian patients are recognised, it is possible that intrinsic differences in paracetamol metabolism may be a contributory factor as well. Our data supports the findings from a recent study demonstrating that $\mathrm{N}$-acetyl cysteine therapy is not cost-effective in the management of Asian patients with paracetamol overdose [26], and treatment algorithms developed in the West may not be appropriate in the East.

\section{Competing interests}

The authors declare that they have no competing interests.

\section{Authors' contributions}

ARM collected the data, performed initial data analysis and drafted the manuscript. NYY provided administrative support. SM conceived and designed the study, performed final data analysis and helped to draft the manuscript. All authors read and approved the final manuscript.

\section{Acknowledgements}

We would like to thank the University of Malaya Short Term Research Grant for their partial funding in the conduct of this study.

\section{Author details}

${ }^{1}$ Division of Gastroenterology, Department of Medicine, University of Malaya, Kuala Lumpur, Malaysia. ${ }^{2}$ Department of Medicine, Hospital Kuala Lumpur, Kuala Lumpur, Malaysia.

Received: 12 May 2012 Accepted: 13 September 2012

Published: 28 September 2012

\section{References}

1. Gunnell D, Hawton K, Murray V, Garnier R, Bismuth C, Fagg J, Simkin S: Use of paracetamol for suicide and non-fatal poisoning in the UK and France: are restrictions on availability justified? J Epidemiol Community Health 1997, 51(2):175-179.

2. Robinson D, Smith AM, Johnston GD: Severity of overdose after restriction of paracetamol availability: retrospective study. BMJ 2000, 321(7266):926-927.

3. Ostapowicz G, Fontana RJ, Schiodt FV, Larson A, Davern TJ, Han SH, McCashland TM, Shakil AO, Hay JE, Hynan L, et al: Results of a prospective study of acute liver failure at 17 tertiary care centers in the United States. Ann Intern Med 2002, 137(12):947-954.

4. Ostapowicz G, Lee WM: Acute hepatic failure: a Western perspective. J Gastroenterol Hepatol 2000, 15(5):480-488.

5. Ayonrinde OT, Phelps GJ, Hurley JC, Ayonrinde OA: Paracetamol overdose and hepatotoxicity at a regional Australian hospital: a 4-year experience. Intern Med J 2005, 35(11):655-660.

6. O'Grady JG, Schalm SW, Williams R: Acute liver failure: redefining the syndromes. Lancet 1993, 342(8866):273-275.

7. Larson AM, et al: Acetaminophen induced acute liver failure: results of a United States multicenter, prospective study. Hepatology 2005, 42:1364-1372

8. Acharya SK, Batra Y, Hazari S, Choudhury V, Panda SK, Dattagupta S: Etiopathogenesis of acute hepatic failure: Eastern versus Western countries. J Gastroenterol Hepatol 2002, 17(Suppl 3):S268-S273.

9. Mohd Zain ZFAl, Ab Rahman AF: Characteristics and outcomes of paracetamol poisoning cases at a general hospital in Northern Malaysia. Singapore Med J 2006, 47(2):134-137.

10. Chan TY, Chan AY, Critchley JA: Paracetamol poisoning and hepatotoxicity in Chinese-the Prince of Wales Hospital (Hong Kong) experience. Singapore Med J 1993, 34(4):299-302.

11. McClain CJPS, Barve S, Devalarja R, Shedlofsky S: Acetaminophen hepatotoxicity: An update. Curr Gastroenterol Rep 1999, 1(1):42-49.

12. Lee WM, Squires RH Jr, Nyberg SL, Doo E, Hoofnagle JH: Acute liver failure: Summary of a workshop. Hepatology 2008, 47(4):1401-1415.

13. DoSM: Population Distribution and Basic Demographic Characteristics. In The 2000 Population and Housing Census of Malaysia Putrajaya; 2000.

14. Schiodt FV, Rochling FA, Casey DL, Lee WM: Acetaminophen toxicity in an urban county hospital. N Engl J Med 1997, 337(16):1112-1117.

15. Gyamlani GG, Parikh CR: Acetaminophen toxicity: suicidal vs. accidental. Crit Care 2002, 6(2):155-159.

16. James LP, Capparelli EV, Simpson PM, Letzig L, Roberts D, Hinson JA, Kearns GL, Blumer JL, Sullivan JE: Acetaminophen-associated hepatic injury: evaluation of acetaminophen protein adducts in children and adolescents with acetaminophen overdose. Clin Pharmacol Ther 2008, 84(6):684-690.

17. Hawton K, Ware C, Mistry H, Hewitt J, Kingsbury S, Roberts D, Weitzel H: Paracetamol self-poisoning. Characteristics, prevention and harm reduction. Br J Psychiatry 1996, 168(1):43-48.

18. Schmidt $L E$, Dalhoff $K$ : The effect of regular medication on the outcome of paracetamol poisoning. Aliment Pharmacol Ther 2002, 16(8):1539-1545.

19. Mills MO, Lee MG: Acetaminophen overdose in Jamaica. West Indian Med J 2008, 57(2):132-134.

20. Brotodihardjo AE, Batey RG, Farrell GC, Byth K: Hepatotoxicity from paracetamol self-poisoning in western Sydney: a continuing challenge. Med J Aust 1992, 157(6):382-385. 
21. Waring WS, Robinson OD, Stephen AF, Dow MA, Pettie JM: Does the patient history predict hepatotoxicity after acute paracetamol overdose? QJM 2008, 101(2):121-125.

22. Proudfoot AT, Wright N: Acute paracetamol poisoning. Br Med J 1970 3(5722):557-558.

23. Rumack BH, Peterson RC, Koch GG, Amara IA: Acetaminophen overdose. 662 cases with evaluation of oral acetylcysteine treatment. Arch Intern Med 1981, 141(3 Spec No):380-385.

24. Prescott LF: Paracetamol, alcohol and the liver. Br J Clin Pharmacol 2000, 49(4):291-301

25. Patel $\mathrm{M}$, Tang BK, Kalow W: Variability of acetaminophen metabolism in Caucasians and Orientals. Pharmacogenetics 1992, 2(1):38-45.

26. Senarathna SG, Sri Ranganathan S, Buckley N, Fernandopulle R: A cost effectiveness analysis of the preferred antidotes for acute paracetamol poisoning patients in Sri Lanka. BMC Clin Pharmacol 2012, 12(1):6.

doi:10.1186/2050-6511-13-8

Cite this article as: Marzilawati et al:: Low rates of hepatotoxicity among Asian patients with paracetamol overdose: a review of 1024 cases. BMC

Pharmacology and Toxicology 2012 13:8.

\section{Submit your next manuscript to BioMed Central and take full advantage of:}

- Convenient online submission

- Thorough peer review

- No space constraints or color figure charges

- Immediate publication on acceptance

- Inclusion in PubMed, CAS, Scopus and Google Scholar

- Research which is freely available for redistribution 